\title{
Kinetics of the Silicon-Silicontetrachloride Reaction in a Flow System
}

\author{
Alstrup, Ole; Thomas, Carl O.
}

Published in:

Journal of The Electrochemical Society

Link to article, DOI:

$10.1149 / 1.2423531$

Publication date:

1965

Document Version

Publisher's PDF, also known as Version of record

Link back to DTU Orbit

Citation (APA):

Alstrup, O., \& Thomas, C. O. (1965). Kinetics of the Silicon-Silicontetrachloride Reaction in a Flow System. Journal of The Electrochemical Society, 112(3), 319-323. https://doi.org/10.1149/1.2423531

\section{General rights}

Copyright and moral rights for the publications made accessible in the public portal are retained by the authors and/or other copyright owners and it is a condition of accessing publications that users recognise and abide by the legal requirements associated with these rights.

- Users may download and print one copy of any publication from the public portal for the purpose of private study or research.

- You may not further distribute the material or use it for any profit-making activity or commercial gain

- You may freely distribute the URL identifying the publication in the public portal

If you believe that this document breaches copyright please contact us providing details, and we will remove access to the work immediately and investigate your claim. 


\title{
Kinetics of the Silicon-Silicontetrachloride Reaction in a Flow System
}

\author{
Ole Alstrup and Carl O. Thomas ${ }^{1}$ \\ Physics Department, Section III, Technical University of Denmark, Lyngby, Denmark
}

ABSTRACT

The kinetics of the heterogeneous reaction

$$
\mathrm{Si}+\mathrm{SiCl}_{4}=2 \mathrm{SiCl}_{2}
$$

have been studied in a flow system with helium as the carrier gas. For this reaction the postulated rate expression

$$
\begin{aligned}
\frac{d \mathrm{Si}}{d t}=-1.0 \times 10^{6} \exp ( & \left.-\frac{67000}{R T}\right) P_{4}^{1 / 2}+9 \exp \left(-\frac{29000}{R T}\right) P_{2} \\
& \mathrm{~g} \mathrm{Si} \mathrm{cm}^{-2} \mathrm{sec}^{-1}
\end{aligned}
$$

was shown to describe the experimental results. The flow system data has been analyzed in terms of quantitatively measurable system parameters. Consequently true rather than apparent constants are found.

The reduction of silicon and germanium tetrahalides in a hydrogen atmosphere is widely used as a method for preparing epitaxial films of these materials. The type reaction is written usually as

$$
\mathrm{MX}_{4}+2 \mathrm{H}_{2}=\mathrm{M}+4 \mathrm{HX}
$$

where $\mathrm{M}$ is the group-IV element and $\mathrm{X}$ is the halogen. This form is not even an accurate indication of the material balance. For example, a variety of other products occurs in the silicon-chlorine process including $\mathrm{SiHCl}_{3}$ and miscellaneous polymeric forms. In spite of the large amount of experimental work in this field, a high level of uncertainty remains as to the mechanism by which hydrogen is involved in the overall process. However, there is a general consensus in the literature [silicon (1-5) and germanium (6-7)] that the type disproportionation

$$
\mathrm{M}+\mathrm{MX}_{4}=2 \mathrm{MX}_{2}
$$

is one of the reactions in the over-all process. The equilibrium for the $\mathrm{Si}-\mathrm{SiCl}_{4}$ reaction following Eq. [2] has been studied quantitatively by Schäfer and Nickl (8-9). They concluded that no other molecular species were present to any significant degree. Bylander (2) and Monchamp, McAleer, and Pollack (5) have studied the disproportionation reaction in a flow system, but no quantitative kinetic data were obtained in either case. Monchamp et al. then used a low-pressure closed system, somewhat similar to that used by Heinecke and Ing (10) in germanium studies, for the investigation of the kinetics of the disproportionation reaction. They found that

$$
\begin{aligned}
& \frac{d N_{o}}{d t}=-8.23 \times 10^{24} \exp \left(-\frac{49100}{R T}\right) P_{4}^{1 / 2} \\
& \text { atoms } \mathrm{Si} \mathrm{cm}^{-2} \mathrm{sec}^{-1}
\end{aligned}
$$

where $N_{o}$ is the number of atoms in the silicon sample divided by its surface area, and $P_{4}$ the $\mathrm{SiCl}_{4}$ pressure. A rate expression of this form indicates that the reaction must go to completion, and that the equilibrium constant must be either zero or infinite. The equilibrium constant is known to have a finite value (8), and consequently the rate expression of Monchamp et al. cannot be strictly valid. We postulate, subject to subsequent experimental verification, that the complete rate expression is of the following form

1 Present address: Department of Physics, University of Tennessee, Knoxville, Tennessee.

$$
\frac{d N_{o}}{d t}=-k_{1}^{\prime} P_{4}^{n}+k_{2}^{\prime} P_{2}^{2 n}
$$

where $P_{2}$ is the $\mathrm{SiCl}_{2}$ pressure $\left(P_{\mathrm{SiCl}_{2}}\right)$ in the reaction zone, and $k_{1}^{\prime}$ and $k_{2}^{\prime}$ are rate constants. In Eq. [4] the factor-of-two relationship between the exponents is a requirement imposed by the form of the equilibrium constant, since this is found to be equal to $P_{2}{ }^{2} / P_{4}$. At high flow rates, i.e., not near equilibrium, $\left|k_{2}^{\prime} P_{2}{ }^{2 n}\right|<<$ $\left|k_{1}^{\prime} P_{4}{ }^{n}\right|$ and Eq. [3] and [4] become similar in form. As one approaches equilibrium at low flow rates, the right-hand term becomes increasingly significant. We have determined the numerical values of $k_{1}^{\prime}$ and $k_{2}^{\prime}$ and $n$. The data, when extrapolated to zero flow rate, yield an equilibrium constant in reasonable agreement with that reported earlier by Schäfer and Nickl (8).

\section{Experimental}

The reaction chamber is shown in Fig. 1. The normal flow direction was in through the larger tube and out through the smaller central tube. The lower linear velocity through the external tube provided better temperature equilibration for the incoming gases. The influence of the flow direction was only detectable for flow rates above about $1 \mathrm{cc} \mathrm{sec}-1$. The close annular fit between the two concentric pieces and the capillary tip on the inner piece was intended to minimize backstreaming of gases. The volume of the reaction zone could be changed by changing the distance which the central piece was inserted into the larger tube.

At the highest flow rates used, the input pressure was less than $10 \mathrm{~mm}(\mathrm{Hg})$ above atmospheric pressure. Since the pressure terms enter to the one-half power and to the first power, the error in neglecting this pressure increment was considered to be negligible.

The flow rate was measured by means of a soap-film flow meter (11). A cold trap and a short capillary were placed between the exit of the reaction chamber and the flow meter to prevent halide products from getting into the flow meter. The flow rate data were

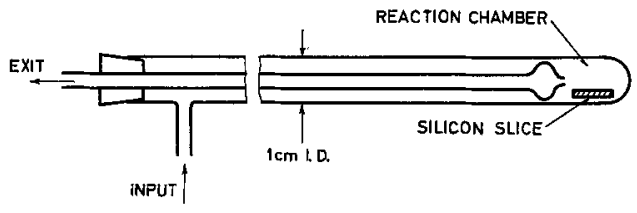

Fig. 1. Quartz reaction chamber 
corrected to standard conditions (cc sec-1 at $25^{\circ} \mathrm{C}$ and $760 \mathrm{~mm} \mathrm{Hg}$ ).

In the range of about $0.2 \mathrm{cc} \mathrm{sec}^{-1}$ to several cc sec-1 the flow control and reproducibility were better than $\pm 5 \%$. At flow rates below about $0.2 \mathrm{cc} \mathrm{sec}^{-1}$ the reproducibility degenerated rapidly. Therefore, at very low flow rates a motor-driven oil piston pump was used. In this way, a known volume of helium was pumped through the reaction chamber in a given time. The flow rate reproducibility was about $\pm 10 \%$.

A platinum-wound Heraeus furnace was used for heating. The furnace profile was flat to $\pm 2^{\circ} \mathrm{C}$ for more than the length of the reaction zone. The temperature was stable to about $\pm 2^{\circ} \mathrm{C}$ for the duration of the runs, usually about $1 / 2 \mathrm{hr}$. The control thermocouple was mounted adjacent to the furnace windings, and the measurement thermocouple was in contact with the end of the reaction chamber. A rather high activation energy was found for the reaction. Consequently the rate will be quite sensitive to the temperature variations, and this may be one of the sources of the scatter in the data.

The silicon slices were cut to a (111) orientation $\left( \pm 0.5^{\circ}\right)$. They were then mechanically polished on both sides to a final thickness of about $0.5 \mathrm{~mm}$. The final polish was with $1 \mu$ aluminum oxide. The slices were then waxed down and sawed to specified dimensions. The area figures used in subsequent calculations include both faces and the total edge area of these slices.

The etch rate of the reaction was determined by weight loss measurements on a microbalance. Blank weight loss runs were made with helium alone. The blank weight losses were consistently lower than $3 \%$ of the smallest weight losses produced by the reaction, so this correction was disregarded.

The downstream deposit in the cooler portion of the system was silicon, with no evidence of polymeric formation.

\section{Mathematical Analysis}

We assume complete mixing in the reactor volume. For this condition, where mixing is very rapid compared to the rate, the composition will be uniform throughout the reaction volume and equal to the output composition. This is of course a limiting condition, but it is apparently fulfilled in the reaction chamber used here as is later shown in the discussion of the results. For this condition the depletion rate of $\mathrm{SiCl}_{4}$ in the reaction chamber is

$$
-\frac{d m_{4}}{d t}=v_{0}\left(\rho_{4}{ }^{\mathrm{o}}-\alpha \rho_{4}\right)
$$

where $m_{4}$ is the weight of the incoming $\mathrm{SiCl}_{4}$ vapor, $p_{4}{ }^{\circ}$ the density of $\mathrm{SiCl}_{4}$ in the incoming gas, $\rho_{4}$ the density of $\mathrm{SiCl}_{4}$ in the reaction chamber, and $v_{0}$ the flowrate of the unreacted gas mixture. $\alpha$ is a correction for gas expansion produced by the chemical reaction and is equal to $\left(1+P_{4}{ }^{\circ}\right) /\left(1+P_{4}\right)$, where $P_{4}{ }^{\circ}$ is the $\mathrm{SiCl}_{4}$ pressure in the incoming gas and $P_{4}$ the $\mathrm{SiCl}_{4}$ pressure in the reaction chamber. Equation [5] may be rewritten as

$$
-\frac{d m_{o}}{d t}=-\frac{M_{0}}{M_{4}} \frac{d m_{4}}{d t}=\frac{M_{0}}{M_{4}} v_{o}\left(\rho_{4}{ }^{0}-\alpha \rho_{4}\right)
$$

where $m_{0}$ is the weight of the silicon sample, $M_{0}$ the atomic weight of $\mathrm{Si}$, and $M_{4}$ the molecular weight of $\mathrm{SiCl}_{4}$. Combined with the postulated rate expression which may be written

$$
\frac{1}{A} \frac{d m_{o}}{d t}=-k_{1} P_{4}{ }^{n}+k_{2} P_{2}^{2 n}
$$

where $A$ is the total surface area of the sample we get

$$
\frac{1}{A} \frac{M_{0}}{M_{4}} v_{0}\left(\rho 4^{\circ}-\alpha \rho_{4}\right)=k_{1} P_{4}^{n}-k_{2} P_{2}{ }^{2 n}
$$

For $P_{4}{ }^{\circ}=0.1 \mathrm{~atm}$ and $P_{4}$ equal to the equilibrium value at $1170^{\circ} \mathrm{C} \alpha$ is equal to 1.023 . This is larger than any value applicable to our experimental conditions and consequently we drop the $\alpha$ term at this point. At larger values of $P_{4}$, the $\alpha$ term can of course become significant. For $\alpha=1$ we have

$$
P_{2}=2\left(P_{4}^{o}-P_{4}\right)=2 \Delta P_{4}
$$

Inserting this in Eq. [8] and converting the $\rho_{4}$ term to $P_{4}$ dimensions by multiplication with $M_{4} / R T$ we get

or

$$
\frac{v_{o}}{A} \frac{M_{0}}{M_{4}} \frac{M_{4}}{R T} \Delta P_{4}=k_{1} P_{4}^{n}-k_{2}\left(2 \Delta P_{4}\right)^{2 n}
$$

$$
\frac{v_{o}}{A} \frac{M_{0}}{R T k_{1}}+\left(\frac{4}{K}\right)^{n}\left(\Delta P_{4}\right)^{2 n-1}=\frac{P_{4}^{n}}{\Delta P_{4}}
$$

where $K$ is the equilibrium constant $=P_{2}^{2} / P_{4}=$ $\left(k_{1} / k_{2}\right)^{1 / n}$. It is significant that for conditions where complete mixing obtains the reactor volume is not one of the system variable or constants.

The derivation ignores the "back-streaming" effect which often can introduce an error at low flow rates. The form of this correction was derived by Merten (12) and used by Thurmond and Frosch (13). We have checked the weight loss from the reaction in our system at zero flow and found it to be about the same magnitude as the blank weight loss. This was done by first blowing $\mathrm{SiCl}_{4}$ through the system for $3 \mathrm{~min}$ to insure that a steady-state condition was established. Then the system was closed and allowed to stand at the reaction temperature for $1 \mathrm{hr}$. The system was then quickly purged with helium and the weight loss measured. After subtracting the calculated weight loss for the first $3 \mathrm{~min}$ (obtained from data in other runs) the difference is then due to back-streaming.

\section{Results and Discussion}

Evaluation of $n .-P_{4}$, the ambient $\mathrm{SiCl}_{4}$ pressure in the reaction chamber, can be determined from the flow rate, the initial $\mathrm{SiCl}_{4}$ pressure $P_{4}{ }^{\circ}$, and the silicon weight loss by using the equation for the material balance

$$
\Delta P_{4}=-\frac{1}{v_{0}} \frac{d m_{o}}{d t} \frac{R T}{M_{0}}
$$

where $-d m_{o} / d t$ is set equal to the weight loss of the sample divided by the time for the experiment. We use these values to construct Fig. 2, which is a log$\log$ plot of etch rate $v s$. $P_{4}$. This neglects the second right hand term of Eq. [7]. A straight line can be drawn through the high flow rate points, with a slope of $n=0.49 \pm 0.01$ in agreement with Monchamp et al. Figure 2 is based on nine runs made at a reaction temperature of $1170^{\circ} \mathrm{C}$ and $v_{0} / A \supseteq 3 \mathrm{~cm} / \mathrm{sec}$. The straight

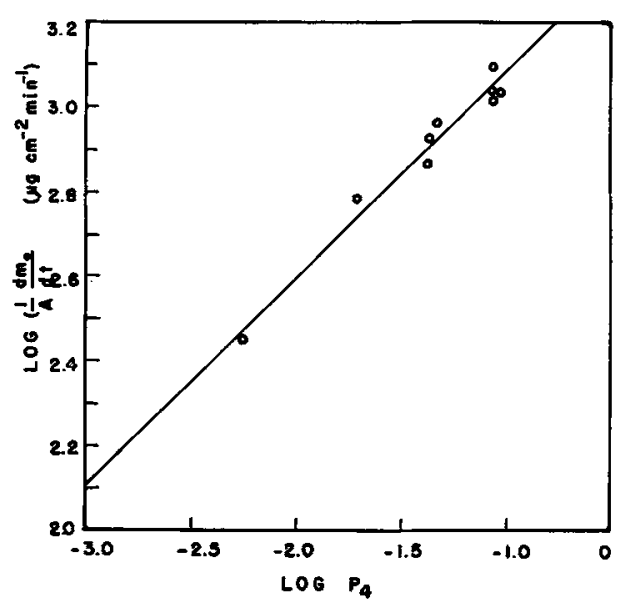

Fig. 2. Etch rate in $\mathrm{g} \mathrm{Si}$ per $\mathrm{cm}^{2}$ per min vs. the $\mathrm{SiCl}_{4}$ pressure. In $\log -\log$ plot the slope is equal to the exponent $n$. 
line shows that one can neglect the second term in Eq. [7] for the high flow rate experiments. The low flow rate data points can lie far from the line. The validity of the above procedure is further supported by Fig. 5 which will be discussed later.

Evaluation of $k_{1}$.-For the special case on $n=0.5$ Eq. [9] simplifies

$$
\frac{v_{o}}{A} \frac{M_{0}}{R T} \frac{1}{k_{1}}+\left(\frac{4}{K}\right)^{1 / 2}=\frac{P_{4^{1 / 2}}}{\Delta P_{4}}
$$

In Fig. 3 we have plotted $P_{4}{ }^{1 / 2} / \Delta P_{4}$ vs. $v_{0} / A$ for the $1170^{\circ} \mathrm{C}$ data. The slope of the line is $M_{0} / R T k_{1}$ and the intercept at $v_{0} / A=0$ is $2 K^{-1 / 2}$, so that we can determine both the rate constant $k_{1}$ and the equilibrium constant $K$. ( $k_{1}$ can also be determined from Fig. 2 and checks within $3 \%$ ). The lower curve is a leastsquares fit to 39 runs. The reaction chamber volume was from 1.5 to $4 \mathrm{cc}$ for this group. The upper curve is for three additional runs at $6 \mathrm{cc}$ volume. For these runs the volume was large enough to invalidate the complete mixing assumption, and to produce an apparently lower rate constant. For the remainder of the runs at other temperatures the reactor volume was kept small enough to be in the complete mixing range and no dependency on the volume was observed.

Schäfer and Nickl (8) give 0.050 (in atm) for the $1170^{\circ} \mathrm{C}$ equilibrium constant. From Fig. 3 we find a value of $0.035 \pm 0.015$ which is in tolerably good agreement with Schäfer and Nickl's result.

The slope of the lower curve in Fig. 3 yields a value of $k_{1}=79 \times 10^{-6} \mathrm{~g} \mathrm{Si} \mathrm{cm} \mathrm{cm}^{-2} \mathrm{sec}^{-1} \mathrm{~atm}^{-1 / 2}$ which is about five times as large as the $k_{1}$ value calculated at $1170^{\circ} \mathrm{C}$ from Monchamp's rate expression.

Runs similar to those previously described were made at reaction temperatures of $1000^{\circ}$ and $1080^{\circ} \mathrm{C}$. For each reaction temperature a least squares plot as shown in Fig. 3 was made. Since the slope is $M_{0} / R T k_{1}$, the rate constant $k_{1}$ at each temperature can be determined. The intercept in each case was again $2 K^{-1 / 2}$. For these temperatures, $K$ was in closer agreement with Schäfer and Nickl's result.

The three values of $k_{1}$ are plotted vs. reciprocal

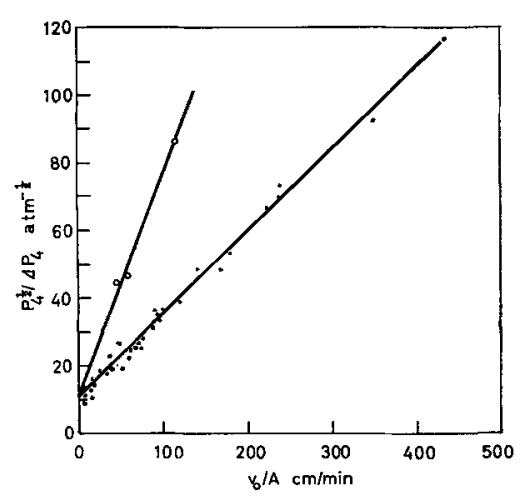

Fig. 3. Data plot based on Eq. [11] for determination of $\boldsymbol{k}_{1}$

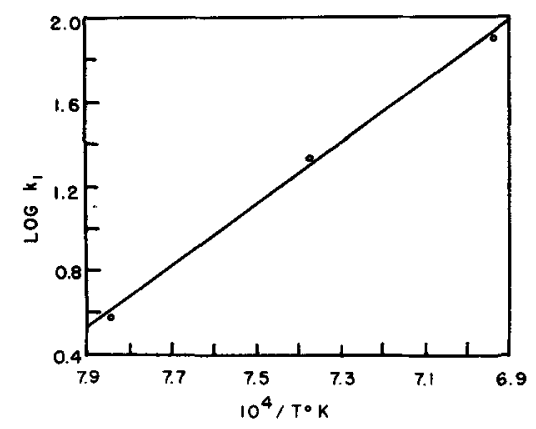

Fig. 4. Temperature dependence of $k 1$ temperatures in Fig. 4. The activation energy is found to be $67 \pm 7 \mathrm{kcal} \mathrm{mole}^{-1}$, which gives

$k_{1}=1.0 \times 10^{6} \exp \left(-\frac{67000}{R T}\right) \mathrm{g} \mathrm{Si} \mathrm{cm}^{-2} \mathrm{sec}^{-1} \mathrm{~atm}^{-1 / 2}$

This activation energy is even higher than that reported by Monchamp et al. Both Monchamp and Heinecke have indicated that for flow system measurements they found a very low apparent activation energy, about $5 \mathrm{kcal}$ in the case of silicon (5). We are unable to account for the great difference between their flow system data and ours. We would expect the apparent activation energy to be lower in the closed system where the mass transport is limited in part by diffusion and convection currents in the gas phase. This could account in part for the difference between 49 kcal reported for a closed system by Monchamp and the $67 \mathrm{kcal}$ found in the present work for an open flow system.

Calculation of $k_{2}$.-One cannot, of course, derive the rate expression from the equilibrium constant directly. However, if the rate expression is correctly formulated in Eq. [4], we can calculate $k_{2}$ and its activation energy from the data available at this point. At equilibrium

$$
k_{1} P_{4}^{1 / 2}=k_{2} P_{2}
$$

and $k_{2}=k_{1} K^{-1 / 2}$. We have found both $k_{1}$ and $K$ as functions of temperature, but since our value of the equilibrium constant is in agreement with Schäfer and Nickl's and the latter is determined with more accuracy we have used their value for calculating $k_{2}$, i.e., we use

$$
K=1.21 \times 10^{10} \exp \left(-\frac{75000}{R T}\right) \mathrm{atm}
$$

Therefore by use of Eq. [12] we can go directly to $k_{2}=9.0 \exp \left(-\frac{29000}{R T}\right) \mathrm{g} \mathrm{Si} \mathrm{cm}^{-2} \mathrm{sec}^{-1} \mathrm{~atm}^{-1}$

and the complete rate expression

$$
\begin{aligned}
\frac{1}{A} \frac{d m_{o}}{d t} & =-1.0 \times 10^{6} \exp \left(-\frac{67000}{R T}\right) P_{4}^{1 / 2} \\
& +9 \exp \left(-\frac{29000}{R T}\right) P_{2} \mathrm{~g} \mathrm{Si} \mathrm{cm}^{-2} \mathrm{sec}^{-1}
\end{aligned}
$$

The two activation energies are consistent with the $H$ value for the reaction as calculated from the heats of formation of the dichloride and of the tetrachloride.

Flow rate dependency.-Rearrangement of Eq. [11] gives

$$
\Delta P_{4}=\frac{k_{1} P_{4}^{3 / 2}}{2 k_{2}+v_{0} M_{0} / A R T}
$$

Figure 5 illustrates the etch rate, stated as weight loss per cc of gas, as a function of the $v_{o} / A$ parameter. The solid line is calculated from Eq. [16] (Recall that $1 / v_{0} \times d m_{o} / d t$ is proportional to $\Delta \mathrm{P}_{4}, \mathrm{Eq}$. [10]) for a reaction temperature of $1170^{\circ} \mathrm{C}$ and $P_{4}{ }^{\circ}$ equal to 0.045 atm. The broken line is calculated using only the $k_{1} P_{4}^{1 / 2}$ term from Eq. [7]. For low flow rates the curve is too high and approaches complete reaction rather than the equilibrium value. For $v_{o} / A \supseteq 3 \mathrm{~cm} / \mathrm{sec}$ one is allowed to disregard the second term in Eq. [15].

By inserting Eq. [10] in Eq. [16] we get

or

$$
-\frac{d m_{o}}{d t}=\frac{k_{1} P_{4}{ }^{1 / 2}}{\frac{1}{A}+2 k_{2} \frac{R T}{M_{0}} \frac{1}{v_{o}}}
$$

$$
-\frac{1}{A} \frac{d m_{o}}{d t}=\frac{k_{1} P_{4}^{1 / 2}}{1+2 k_{2} \frac{R T}{M_{0}} \frac{A}{v_{o}}}
$$




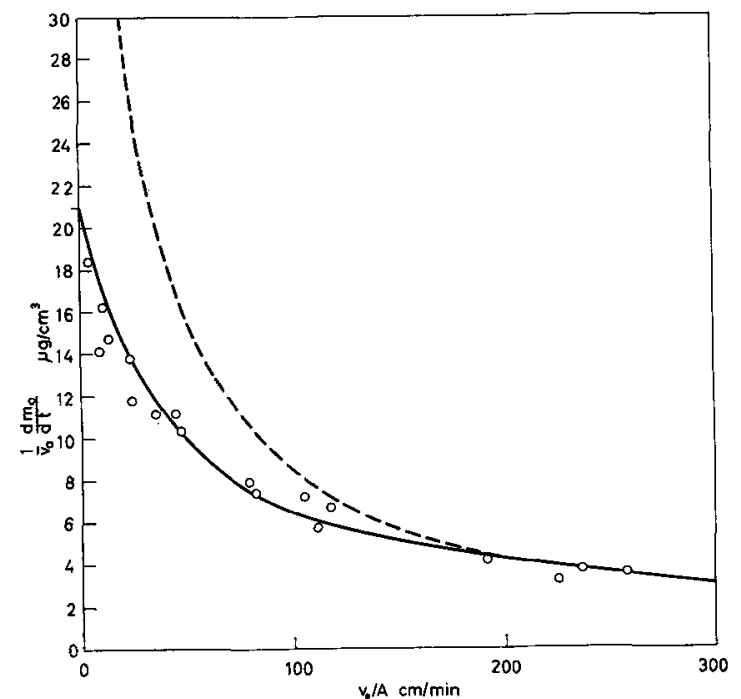

Fig. 5. Etch rate in $\mathrm{g} \mathrm{Si}$ per $\mathrm{cc}$ of the gas vs. the flow rate divided by the sample area.

At sufficiently low flow rates Eq. [18] gives

$$
\begin{aligned}
-\frac{1}{A} \frac{d m_{o}}{d t} \cong \frac{M_{0}}{R T} \frac{k_{1}}{2 k_{2}} & \frac{v_{o}}{A} P_{4}^{1 / 2} \\
& =\frac{M_{0}}{R T}\left(\frac{K}{4}\right)^{1 / 2} \frac{v_{o}}{A} P_{4}^{1 / 2}
\end{aligned}
$$

At high flow rates

$$
-\frac{1}{A} \frac{d m_{0}}{d t} \cong k_{1} P_{4}^{1 / 2} \cong k_{1} P_{4}^{01 / 2}
$$

By plotting $1 / A \times d m_{o} / d t$ vs. $v_{o} / A$ as with Eq. [19] and [20] one gets a curve with asymptotes in "both ends.' From the asymptotes one can calculate $k_{1}$ and $K$. However the low flow rate region often is so small that the asymptote is determined with a high uncertainty.

Equation [17] and Eq. [18] are consistent as to asymptotes. However if one uses samples of different area, it is seen from Eq. [17] that one cannot get a curve in the intermediate region by plotting $d m_{o} / d t v s$. $v_{0}$. We see that the flow dependency is expressed by the ratio $v_{o} / A$ rather than by $v_{0}$.

The dimensions of $v_{0} / A$ are $\mathrm{cm} / \mathrm{sec}$, a linear velocity, but should not be construed as being the actual linear velocity of the gas in the system, since the area is that of the sample and not the cross section of the reactor. Mathematical normalization to unit area, introduced in Eq. [7] leads to the $v_{0} / A$ form.

General comments.-The temperature measurement of the reaction chamber is done with a thermocouple placed outside the reaction chamber. Because of the possibility of a temperature difference between the outside and inside of the reaction chamber there may be a systematic error in the temperature measurement. There are different sources of error. The incoming gas may not be sufficiently warm. As mentioned previously this was the case when the gas was let in through the narrow inner tube. When we use the outer tube the temperature profile in the furnace is so flat that the gas obtained the right temperature at all flow rates. This can be seen by the following argument. If the gas temperature is lower than the stated reaction temperature, the temperature difference will increase with increasing flow rate as the time of heat transfer per cc of gas from the wall will decrease. Consequently for two "identical" experiments, where $v_{0} / A$ is the same but $v_{0}$ is different, we should get a lower etch rate for the experiment at higher flow rate. This is not observed within the experimental uncertainty. Another source of error could be the heat of the reaction. Also, an error may appear since there may be a tem- perature difference between the gas and the furnace walls. In fact some later experiments carried out in a quite different system gave etch rates that all were $10 \%$ higher than those given here. It may be explained by the two last sources of error. Including these experiments in the calculations would change $k_{1}$ about $15 \%$ and $K$ about $40 \%$, whereas $n$ would be unchanged. These figures may indicate the uncertainty of the experiments.

Comparing our results with those of Monchamp et al. we see that the $n$-value is the same whereas we get different values for the activation energy of $k_{1}$. The difference is so large that it cannot be explained by an error in our temperature measurement. We believe it more likely that Monchamp's etching is partly diffusion limited. This is the case for our experiments with the large reaction chamber as shown in Fig. 3 (upper line). The value of $k_{1}$ is lower but the value of $n$ is still 0.5 .

Another difference between Monchamp's and our results is that we in the rate expression use the actual pressures of $\mathrm{SiCl}_{4}$ and $\mathrm{SiCl}_{2}$ in the reaction chamber, whereas Monchamp apparently uses the initial pressure $P_{4}{ }^{\circ}$ or an over-all pressure $P_{4}+P_{2}$. However this cannot explain the difference in our $k_{1}$ values.

The high activation energy for the etching reaction and the fractional order of the reaction imply that the rate limiting step is surface adsorption or desorption as suggested by Monchamp et al. In this case we would expect to see a relationship to the surface roughness factor. However no difference in etch rate was observed on chemically polished and on lapped samples. In most of the runs, the total thickness reduction was about $250 \mu$. Consequently the initial roughness produced by different surface treatments would be smoothed out early in the runs, and the roughness variation could be hidden, along with other experimental variables, in the standard deviation. There was no detectable rate difference between the (111), (110), and (100) planes. Also, there was no noticeable preferential development of crystal faces near the edges or corners of the samples. On the other hand if the rate-limiting step is surface adsorption or desorption, one would expect $n$ to vary with pressure, which is not found in the pressure region used.

\section{Acknowledgments}

The authors wish to thank Mrs. I. Lund and Mr. $\mathrm{S}$. Mathiesen for preparing the samples and assisting with the runs; C. D. Thurmond and N. I. Meyer for helpful discussion: the Bell Telephone Laboratories and Haldor Topsøe for contributing the materials used in the work.

Manuscript received July 27, 1964; revised manuscript received Oct. 28, 1964. This paper was abstracted in part from one submitted in partial fulfillment of the requirements for the Lic. Techn. degree by one of the authors (O.A.) and the work was supported in part by grants from the United States Educational Foundation in Denmark and from the American Scandinavian Foundation in New York.

Any discussion of this paper will appear in a Discussion Section to be published in the December 1965 JOURNAL.

\section{REFERENCES}

1. W. Steinmaier, Philips Research Repts., 18, 75 (1963).

2. E. G. Bylander, This Journal, 109, 1171 (1962).

3. R. C. Newman and J. Wakefield, ibid., 110, 1068 (1963).

4. H. Basseches, R. C. Manz, C. O. Thomas, and S. K. Tung, in "Proceedings of the AIME Technical Conference on the Metallurgy of Semiconductor Materials," Interscience Publishers, New York (1962).

5. R. R. Monchamp, W. J. McAleer, and P. I. Pollack, This Journal, 111, 877 (1964).

6. J. J. Grossman, ibid., 110, 1065 (1963). 
7. N. Kyle and J. J. Grossman, Paper presented at New York Meeting of the Society, Oct., 1963.

8. H. Schäfer and J. Nickl, Z. anorg. u. allgem. Chem., 274, 250 (1953).

9. H. Schäfer, ibid,, p. 265.

10. W. J. Heinecke and S. Ing, J. Appl. Phys., 32, 1498 (1961).

11. A. I. M. Keulemans, "Gas Chromatography," pp. 56-57, Reinhold Publishing Co., New York (1957).

12. U. Merten, J. Phys. Chem., 63, 443 (1959).

13. C. D. Thurmond and C. J. Frosch, This Journal, 111, 184 (1964).

\section{LIST OF SYMBOLS}

A surface area of the sample.

$\alpha$ correction factor to account for the volume ex-

$K$ pansion in the reaction chamber $k_{1}, k_{2}$ rate constants, associated with $P_{4}$ and $P_{2}$, respectively.

$M_{0} \quad$ atomic weight of $\mathrm{Si}$

$M_{4}$ molecular weight of $\mathrm{SiCl}_{4}$.

$m_{o} \quad$ weight of Si sample.

$N_{0}$ number of Si atoms in the sample per unit surface area.

$P_{4}{ }^{\circ}=P^{\circ}{ }_{\text {SiCl4 }}=\mathrm{SiCl}_{4}$ pressure in the incoming gas.

$P_{4}=\mathrm{P}_{\mathrm{SiCl} 4}=\mathrm{SiCl}_{4}$ pressure in the reaction zone.

$P_{2}=\mathrm{PSiCl}_{2}=\mathrm{SiCl}_{2}$ pressure in the reaction zone.

$\Delta P_{4}=P_{4}{ }^{0}-P_{4}$.

${ }_{R} P^{4}{ }^{\circ}-P_{4}$.

$\rho_{4}{ }^{\circ}$ density of the incoming $\mathrm{SiCl}_{4}$.

$\rho_{4}$ density of $\mathrm{SiCl}_{4}$ in the reaction chamber.

$T$ absolute temperature.

$t$ time (sec)

$v_{o}$ flowrate of the incoming gas mixture (cc/sec) corrected to $298^{\circ} \mathrm{K}$ and $1 \mathrm{~atm}$.

\title{
Localized Enhanced Diffusion in NPN Silicon Structures
}

\author{
R. Gereth, P. G. G. van Loon, and V. Williams \\ ITT Semiconductor, Shockley Laboratory, Palo Alto, California
}

\begin{abstract}
Extensive studies of the Emitter Dip Effect (EDE) in npn silicon structures are reported. Typically, $1 \mathrm{ohm}-\mathrm{cm}$ n-type silicon starting material was used. Boron diffusion into this material resulted in a $0.7 \mu$ base depth and surface concentrations of $1.8 \times 10^{20} \mathrm{~cm}^{-3}$. The emitter regions had surface concentrations of $3 \times 10^{20} \mathrm{~cm}^{-3}$ and $0.4 \mu$ junction depths. The dip was typically $0.3 \mu$, i.e., the base penetrated $0.3 \mu$ deeper under the emitter than elsewhere. Important experimental findings are: $(A)$ Crucible grown, zone refined, and epitaxial silicon give the same results. $(B)$ The EDE occurs only if phosphorus doping is sufficient to overcompensate the base doping. (C) Multiple emitter diffusion causes multiple dips. (D) Slow cooling from diffusion temperature enhances the dip. $(E)$ An enhanced boron diffusion constant in the base layer apparently causes the dip rather than the rejection of boron by the region of high phosphorus concentration. (F) The dip is not present for lightly doped $\left(10^{17} \mathrm{~cm}^{-3}\right)$ base layers.
\end{abstract}

Localized enhanced diffusion of the base collector junction underneath the emitter regions has been observed in double diffused high-frequency transistors (1-3). This phenomenon is often referred to as Emitter Dip Effect (EDE). Not very much attention has been given to the EDE in the relevant literature during recent years. This was mainly due to lack of reproducibility complicating the study of the EDE and its theoretical explanation. The EDE was first reported by Miller (1), who described the phenomenon and suggested the possibility that the effect was caused by impurity interactions such as published by Reiss et al. (4) for lithium in germanium. Later, the EDE was discussed by Baruch and co-workers (2). Based on a vacancy enhanced diffusion mechanism they developed an hypothesis which partially explained the EDE observed in a npn structure made with gallium base diffusion.

The earliest work which was done in the course of the investigation reported here was concerned with the reproducibility of the effect. Previously, the EDE had been observed only sporadically and was found to be connected in some way with the time and temperature of predeposit of both the base and the emitter dopants, subsequent diffusion and oxidation steps, and operator technique, as well as general cleanliness of the furnaces. After a schedule had been found which gave reproducible results from run to run, intensive studies were made to establish the experimental conditions for the creation of the EDE. Most emphasis was put on a shallow diffused silicon npn transistor. The experiments were extended later to pnp structures.

\section{Experimental Results}

Starting material and standard diffusion schedule.The starting material used in the majority of the experiments was $n^{-} n^{+}$epitaxial material obtained from
Merck, Monsanto, Allegheny; and Texas Instruments. The vapor grown $\mathrm{n}^{-}$silicon film was about $10 \mu$ thick and had a resistivity of $1 \mathrm{ohm}-\mathrm{cm}$, corresponding to a carrier concentration of $5 \times 10^{15} \mathrm{~cm}^{-3}$. The resistivity of the $\mathrm{n}^{+}$substrate ranged from 0.002 to $0.04 \mathrm{ohm}-\mathrm{cm}$. The same results were obtained when experiments were carried out using crucible grown silicon material of equivalent doping level. The schedule which was followed in most of the work is described below and illustrated in Fig. 1.

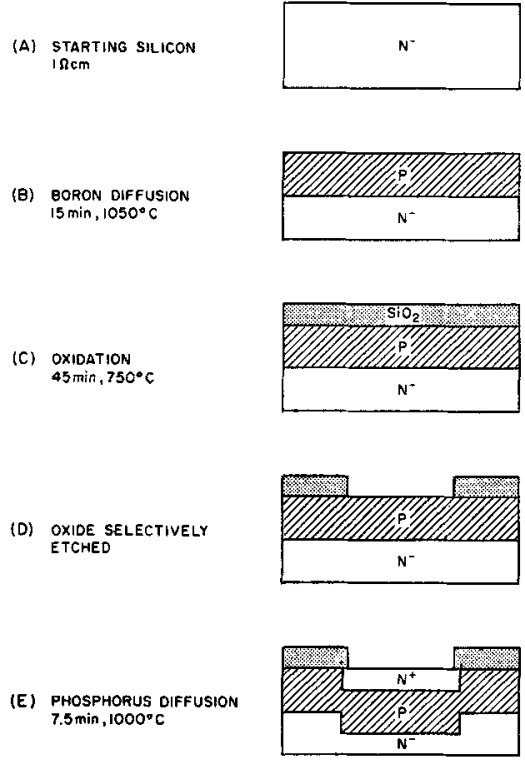

Fig. 1. Processing steps for fabrication of shallow diffused npn silicon structures. 